\title{
Positive Behavior Support in Physical Education: A Case from a Pre-service Field Experience
}

\author{
Alice M. Buchanan \\ School of Kinesiology \\ Vanessa Hinton \\ Department of Special Education, Rehabilitation, and Counseling \\ Auburn University
}

\begin{abstract}
The purpose of this paper is to describe the behavior effects of positive behavior interventions and support (PBIS) in a pre-service physical education field experience. PBIS, a way of managing and improving student behavior, has a history of success in classrooms, but little research has been done on its use in physical education. Teacher candidates in elementary education taught physical education to fiftyfour students aged 4-10 who came to the university campus from a local day care center. Behavior marks were taken before and after the PBIS intervention was implemented. Procedural integrity was scored at $93 \%$, and inter-rater reliability was $100 \%$. We found significant differences in students' total behavior marks before and after receiving instruction with PBIS. Significant differences were found for three of the five rules. This study supports previous research showing leveled supports such as behavior contracts, social stories, and visual prompts are successful management strategies in physical education.
\end{abstract}

Keywords: tiered support, motor skills, challenging behavior.

\section{Introduction}

Physical educators, like all teachers, must occasionally deal with problematic student behavior. Many teachers, however, report that they have difficulty creating an environment which not only is conducive to learning, but also facilitates cooperation and self-regulation (Lavay, Henderson, French, \& Guthrie, 2012). The purpose of this paper is to determine how the use of positive behavior interventions and support (PBIS) effects children's behavior in a preservice physical education field experience. PBIS, a way of managing and improving student behavior, has an established history of success in the classroom, but little research has been done on its use in physical education. Therefore, our research question is: 
To what extent does the use of PBIS improve children's behavior in a physical education field setting?

\section{Behavior Management Research in Physical Education}

Researchers are clear that physical educators need further development of management skills (Kulinna, Cothran, \& Regualos, 2006). Even students recognize that their misbehavior frustrates teachers, interferes with instruction, and reduces the time students participate and learn (Cothran, Kulinna, \& Garrahy, 2009; Kulinna et al., 2006). Sometimes teachers blame the students for the misbehavior rather than assuming responsibility for it themselves, expecting the students to behave as the teachers did at that age (Fernandez-Balboa, 1991). Cothran et al. (2009) applied attribution theory to the question of why students behaved the way they did, as well as what teachers believed the reasons were. Both groups attributed student misbehavior to external, uncontrollable factors. For example, in many cases teachers attributed student misbehavior to the child's home life, while students said they misbehaved when the classes were boring. Neither group seemed able to acknowledge that they may have some responsibility for the problems. Both participant groups acknowledged that student behavior was often caused by student attention seeking. Yet, both teachers and students recognized that student misbehavior negatively affected class time, class activities, and members of both groups' attitudes. As users of PBIS seek to determine antecedent behaviors (CITE), attributions can offer insight into the things that may trigger a behavior change.

Lavay and his colleagues (2012) stressed the importance of preventive techniques based on the notion that about $80 \%$ of misbehavior can be prevented by the teacher being positive and proactive (Lavay, French, \& Henderson, 2006). Most physical education teacher education (PETE) programs acknowledge the importance of preventive behavior management, as well class management in general. In PETE programs that teach behavior management models, $70 \%$ used a behavioral approach (such as contingencies and conditioning), while $74 \%$ used a humanistic model (such as character education, cooperative learning, or responsibility) (Lavay et al., 2012). While PBIS, with its roots in applied behavior analysis, falls primarily into the former category, its considered use has been shown to improve behavior, and in some cases may facilitate student selfregulation (Voorhees, Walker, Snell, \& Smith, 2013).

\section{Positive Behavior Interventions and Support}

Positive Behavior Interventions and Support (PBIS) is an alternative to what educators know as traditional classroom management techniques (Dunlap et al., 2000; LaVigna \& Willis, 2012; Simonsen \& Sugai, 2013). Traditional practices are reactive and often punitive, and research demonstrates that punitive approaches are not effective and can in fact worsen already inappropriate behaviors (LaVigna \& Willis, 2012; Simonsen \& Sugai, 2013). Many schools have found PBIS to be successful in improving student behavior. Indeed, a study by Muscott, Mann, and LeBrun (2008) found the use of schoolwide PBIS decreased the amount of office disciplines referrals by $28 \%$. 
PBIS is a multi-tiered support system that places emphasis on proactive ways to teach children strategies for replacing challenging behaviors with appropriate behaviors (OSEP, 2015). Tier I is core behavior management, Tier II is supplemental behavior instruction that targets behavior needing improvement, and Tier III is intensive behavior intervention in which a functional behavior assessment determines the purpose of the challenging behavior (Johnson, Mellard, Fuchs, \& McKnight, 2006; Scott, Alter, Rosenberg, \& Borgmeier, 2010).

Important components for effective use of PBIS in physical education are (a) foregrounding specific problem behaviors: what the student may do, where the student may do it, and when the behavior may occur; (b) interventions documented to effectively increase student success; (c) consistency in implementation among faculty/staff; and (d) formative assessment to monitor outcomes (Scott et al., 2010). A few studies have examined targeted supports or PBIS in physical education (Alstot, 2012; Hinton, Buchanan, \& Rudisill, 2016; Rosser-Sandt \& Frey, 2005; and Zimbelman, Paschal, Hawley, Molgaard, \& Romain, 2007). Alstot examined the effects of a token economy on rope jumping behaviors of students in a physical education classroom. He shows a functional relation through an alternating treatment research design. In another study researchers (Hinton et al., 2016) investigated effects of PBIS in a summer camp for students who were diverse and attended school in a rural system. Leveled supports include a token economy system, behavior contracts, and precorrection techniques. Findings revealed a significant decrease in challenging behaviors when students received instruction with PBIS. Rosser-Sandt \& Frey explored social stories (Gray \& Garand, 1993) to teach students with Autism Spectrum Disorder to wear an accelerometer in physical education class. The students wore the accelerometer and the authors make recommendations to teach social behaviors in physical education such as waiting for a turn and sharing equipment. Zimbelman and colleagues (2007) taught educators how to implement visual schedules to increase the activity levels of students. They explain that sixty-four percent of the teachers stated the use of visual schedules were effective in their physical education instruction.

Behavior management in movement settings, while similar to the general education classroom, also has some nuanced differences (Buchanan \& Brock, 2016). The expectation of movement presents an environment with challenges that differ from the general classroom. Elementary education teachers are expected to be able to teach and manage children in many instructional environments, including physical education. To that end, we investigated the use of PBIS by elementary education teacher candidates in a physical education setting.

\section{Method}

This study was done in two undergraduate summer school classes in a large research university in the Southeast region of the United States. Elementary education teacher candidates (TCs) took this course to learn how to teach 
physical education to children. The teacher candidates were seniors who were to begin their internship (student teaching) the following semester.

\subsection{Participants}

Fifty-four students aged 4-10 years came from a program in a local day care to campus twice per week to serve as students for the classes taught by the teacher candidates. Forty-nine of the children were African-American, and five were Caucasian. There were 21 girls and 33 boys. We divided the children into eight groups by age, with approximately five to seven children per group, and gave each group a color name (blue, green, etc.). The ages in the groups were two groups of 4 year olds, two groups of five year-olds, one of 5-6, one of 6-7, one of 8-9, and one of 9-10. Approval for the study was obtained from the Auburn University Institutional Review Board for Human Subjects Research, as well as the representatives of the Board of Directors of the daycare center. Custodial guardians(s) of each child provided informed consent.

\subsection{Setting}

The teaching laboratory portion of the classes took place in a large athletics coliseum on the playing floor. Each lab lasted 75 minutes, and the groups of children rotated to each station, attending three stations per lab day. Lessons lasted about 20 minutes. Although the groups of children were very small (5-7), other aspects of the teaching labs made them similar to a physical education class. These were (a) a specific set of rules for behavior, (b) teacher-made lesson plans with goals, (c) coed groups, and (d) the diverse range of skill levels within each group. The teacher candidates were in pairs, and one taught using the skill theme approach (Graham, Holt-Hale, \& Parker, 2012) while the other documented behavior using the behavior log. Activities taught were locomotor skills, jumping and landing, throwing and catching, bowling (underhand roll), chasing/dodging/ and fleeing, kicking and punting, dribbling with feet, dribbling with hands, balance, tumbling, and rhythms and dance. They also taught movement concepts using a parachute or scooters.

\subsection{Measures}

For this quasi-experimental study we used pre-and post-test measures to document behavior differences with PBIS. These data consisted of behavior marks documented by the non-teaching teacher candidate (see Figure 1 for an example). Behavior marks were the dependent variable because they could be recorded during the comparison condition as well as the PBIS treatment condition. Behavior marks were recorded for the first two weeks of the teaching lab during the comparison condition in which no PBIS was implemented. Data collected during the comparison condition, along with observation, were used to determine which, if any, students more behavior supports (i.e., tier II or the more intensive tier III). The documentation log had the rules in a horizontal row, and the children's names in a vertical column. The TC documenting the challenging behavior did not interact with the children, but rather stood silently recording behavior by making a tick mark each time a child engaged in a behavior that broke a rule. Behavior marks were recorded for the next four weeks during the treatment condition in which PBIS was implemented. 
Examples were holding the equipment while the teacher talks, helping a friend with a skill, or even making eye contact with a teacher. The same group of children participated in the comparison and treatment conditions.

Behavior Marks TIER I - Make a check beside the name and under the appropriate behavior to indicate positive behaviors.

EVALUATORS DATE

\begin{tabular}{|c|c|c|c|c|c|c|}
\hline $\begin{array}{l}\text { BEHAVIOR } \\
\text { MARKS } \\
\text { TIER I }\end{array}$ & Name & $\begin{array}{l}\text { Respect } \\
\text { Everyone }\end{array}$ & $\begin{array}{l}\text { Follow } \\
\text { Directions }\end{array}$ & $\begin{array}{l}\text { Stay } \\
\text { in } \\
\text { Your } \\
\text { Work } \\
\text { Area }\end{array}$ & $\begin{array}{l}\text { Respect } \\
\text { Equipment }\end{array}$ & $\begin{array}{l}\text { Play } \\
\text { Safely }\end{array}$ \\
\hline & QUONTELL & & & & & \\
\hline & MARK & & & & & \\
\hline & KELVIN & & & & & \\
\hline & JAIME & & & & & \\
\hline & ALEXIS & & & & & \\
\hline & $\mathrm{NASH}$ & & & & & \\
\hline & VALERIE & & & & & \\
\hline
\end{tabular}

Figure 1. Behavior log example (names are pseudonyms)

\subsection{Rules for Behavior}

The five rules for children's behavior were stated positively and concisely. Then when the teacher instructed the children on the rules before activity, the students were prompted to provide examples and non-examples. Following are the rules and some examples provided by the children:

1. Respect everyone. Positive examples: don't be a bully, help a person up when they fall, speaking respectfully to everyone. Negative example: taking away someone's ball.

2. Follow directions. Positive example: do what the teacher says. Negative example: not participating when told to do so. 
3. Stay in your work area. Positive example: go with your group when rotating. Negative example: going to a different station to be with a friend.

4. Respect Equipment. Positive example: use the equipment right. Negative examples: hitting the floor with the hockey stick, kicking a volleyball.

5. Play safely. Positive example: make sure you have enough space between your scooter and your friend's scooter. Negative example: don't hit someone with the hockey stick.

\subsection{PBIS Implementation and Tiered Interventions}

PBIS treatment was implemented within the three tiered framework described above in the literature review. In this section procedures for each tier are described.

2.5a Tier I. All students received tier I. In addition to stating the rules at the beginning of the teaching lab, during the PBIS intervention the rules were visually displayed on a poster. The TCs explicitly re-taught the rules before starting the station activity, prompting students to repeat the rules, and asking students to give examples of what following the rules would look like and what not following the rules would look like. Therefore, students heard the rules at least three times during the teaching lab. By contrast, in the comparison condition TCs reviewed the rules at the beginning of the teaching lab, but the rules were not posted, nor were they taught again.

In addition to explicit repetition of the rules, children were reinforced for positive behavior with 5 minutes of free time at the end of each station, during which they could use the extra equipment (such as hula hoops and balls) that had been distributed, or continue to work on the same skills. For each station every child who earned at least two positive marks earned his or her free time. Students who earned more than the required two marks were considered to have gone "above and beyond", and were allowed to choose an item from the treasure box, a box of small toys from which children who exceeded behavior expectations could choose. We used a bell to signal free time for the station, and a whistle to tell TCs that it was time to transfer to the next station. When the children rotated the TCs passed along the color group's clipboard with the information and behavior mark recording sheet.

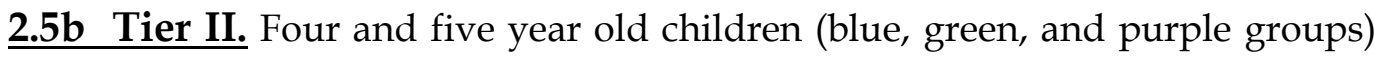
who had not yet begun kindergarten received tier II. This was due to the number of behavior marks they received in the comparison condition, as well as their age and/or lack of school-based experiences. For these students tier II consisted of a social story read at the beginning of the station. The story was written by the researchers, spiral bound, and had text and visuals that showed how to behave appropriately in physical education. Children in tier II had to earn three positive behavior marks in order to have free time at the end of the station. Additionally, TCs had a pocket chart display with brightly colored cards so that children could see how many positive marks they had earned. Finally, the gold group, 
comprised of 5 and 6 year olds, also received tier II. The children in the gold group were a little older than the others, and they received a behavior contract which was read to them at the beginning of each station. All of the children receiving tier II had to earn 3 behavior marks by following the rules listed in the contract in order to earn free time at the end of the station. Each child who received three positive marks, at each station, for two days in a row was allowed to choose an item from the treasure box.

2.5c Tier III. Due to the number of behavior marks, we identified two students, both of whom were girls, who would receive tier III intervention: Madeline (all names are pseudonyms), a 6 year old in the gold group and Kaliyah, a 7 year old in the silver group. A functional behavior assessment (FBA) was conducted by the second author. The purpose of an FBA is to determine the purpose of each student's behavior using antecedent-behavior-consequence. The observer uses a recording form and watches the child in particular situations in order to determine things that might cause that child to display negative behavior. Once that is determined the teacher can plan accordingly ways to decrease a student's negative behavior. For example, an FBA may determine that a boy with autism spectrum disorder cries each time the basketballs are brought out in the cart. Further observation reveals that the squeaky noise made by the cart is a hurtful, annoying sound to which he is very sensitive. The teacher can then solve the problem by finding an alternative way to carry the basketballs.

Kaliyah, displayed challenging behaviors in order to gain attention. She also worked better when she had a peer with her, however, observation showed that the other children avoided playing and interacting with Kaliyah. We assigned a peer to always stay with Kaliyah. Kaliyah earned her Tier III positive marks for cooperating with the peer, and the peer received marks for helping. A separate clipboard held a log on which to document Kaliyah's and her friend's cooperative behaviors. If both of them earned enough positive marks they each were able to choose an item from the treasure box.

Madeline displayed challenging behaviors in order to gain control over her peers and environment. She was given the same contract for following the rules as the rest of the gold group. However, rather than receiving a mark on a page, she was able to place a "tiger paw" token (a laminated image of a tiger paw) on her own clipboard. Thus, Madeline was given ownership in following the rules, and placing her own token on a clipboard served her need to be in control. When Madeline earned enough tiger paws she was able to choose an item from the treasure box.

\subsection{Teacher Training}

Before beginning PBIS treatment the teacher candidates who implemented activities were trained on how to document behavior using log sheets. After two weeks of collecting comparison data, we trained TCs how to review the rules unambiguously at the beginning of the station activity, and how to ask students to provide examples of following the rules and not following the rules. We also trained them on how to implement a token economy, how to use a behavior 
contract, and how to read a social story to the young children before starting the activity. They practiced the PBIS procedures for a week before demonstrating mastery. A manipulation checklist documented TCs' mastery of the PBIS procedures. If the TCs struggled at all with the documentation or the steps in which to implement PBIS, we reviewed them again until they were confident with the process.

\subsection{Procedural Integrity}

Using a checklist, the researchers observed and recorded instruction throughout the PBIS treatment condition in order to document that PBIS instruction was implemented accurately. The fidelity checklist included (a) reviewing the rules with positive language, (b) providing examples of following the rules, (c) providing examples of not following the rules, (d) explaining what behaviors would lead to earning behavior marks or tiger paws, (e) recording behaviors using the behavior log, (f) allowing students to turn in behavior marks or tiger paws for reinforcers, and (g) providing reinforcers for students in tier II who earned the required positive marks based on their behavior. Procedural integrity was calculated as $93 \%$.

\subsection{Inter-rater Reliability}

We documented inter-rater reliability daily for all of the behavior logs and the procedural integrity checklists. The teacher candidates recorded behaviors in the behavior logs. The two researchers separately tallied the behavior logs and procedural integrity checklists in order to confirm consistency. The process of calculating inter-rater reliability is to divide the total number of agreements between the two researchers by the total number of observations, and then multiply that number by 100 (Poling, Method, \& LeSage, 1995). Inter-rater reliability was $100 \%$ for the behavior logs and $93 \%$ for procedural integrity.

\section{Results}

The researchers conducted paired samples $t$ - tests to evaluate the differences between behavior marks students received before and behavior marks received after having instruction with PBIS. Differences were analyzed for the total behavior marks and for each rule. We found a significant difference between students' total behavior marks before and after receiving instruction with PBIS $(M=3.1, S D=3.64, t(53)=6.26, p=0.00)$. A significant difference in students behavior marks for displaying respect for everyone before and after receiving instruction with PBIS was found $(M=1.31, S D=3.8, t(53)=2.54, p=0.01)$. Students' behavior marks for staying in the work area before and after receiving instruction with PBIS were significantly different $(M=.981, S D=3.23, t(53)=$ 2.23, $p=0.03)$, as were students' behavior marks for respecting equipment $(M=$ $.796, S D=2.55, t(53)=2.29, p=0.03)$. We did not find statistically significant differences for students' behavior marks regarding rules for following directions and playing safely. The means and standard deviations for behavior marks based on the total and by each rule are presented in Table 1. 
Table 1: Mean and standard deviation for behavior marks

\begin{tabular}{lll}
\hline Rule Pre and Posttest & Mean & SD \\
\hline \hline Total Pre & $4.65^{* *}$ & 4.10 \\
Total Post & $1.55^{* *}$ & 2.00 \\
Respect Everyone Pre & $3.26^{* *}$ & 3.97 \\
Respect Everyone Post & $1.94^{* *}$ & 2.51 \\
Follow Directions Pre & 10.63 & 10.08 \\
Follow Directions Post & 7.93 & 9.93 \\
Stay in Area Pre & $2.24^{*}$ & 3.43 \\
Stay in Area Post & $1.26^{*}$ & 1.85 \\
Respect Equipment Pre & $1.85^{*}$ & 2.56 \\
Respect Equipment Post & $1.06^{*}$ & 2.24 \\
Play Safely Pre & .98 & 1.22 \\
Play Safely Post & .67 & 1.32 \\
\hline * Significant at $\mathrm{p} \leq .05$ & & \\
** Significant at $\mathrm{p} \leq .01$ & & \\
\hline
\end{tabular}

\section{Discussion}

We implemented PBIS using the recommended tiered instruction. For tier I (core effective management) the rules were posted and coupled with positive reinforcement. The teacher candidates went over the rules at the beginning of class and at the beginning of each station, and asked students to state examples of following and not following the rules. This was a way of embedding the rules into the class procedures and made teacher expectations very clear, and students were constantly reminded of what positive behaviors were. The results indicate that such rules instruction, that which is expected to be effective for $80 \%$ of the students, was successful. Tier II intervention consisted of the same strategies as tier I, plus a social story or a behavior contract, and a visual showing the positive behavior marks when earned. Social stories are effective because they provide students with a visual of the expected behaviors with age appropriate pictures of children following the rules. They provide students with the social information needed to adhere to classroom protocol (Sandt, 2008). The behavior contract (Simonsen, Fairbanks, Briesch, Meyers, \& Sugai, 2008) is a way of achieving student buy-in for their own behavior by having them sign a list of the rules (or print their name) that the teacher candidate reads to them. For example, researchers (Hawkins et al., 2011) demonstrated the success of using behavior contracts in reducing antisocial behavior in boys diagnosed with autism spectrum disorder. While the behaviors for which we contracted were not as severe as those Hawkins studied, we experienced similar success, as such a strategy embeds accountability so that students were able to exhibit appropriate behavior as defined by the rules. The limited use of PBIS interventions such as behavior contracts and social stories in physical education, coupled with the described success of PBIS in special education as well as the general classroom, indicate the need for further use and documentation of such strategies. RosserSandt and Frey (2005) investigated the use of social stories in the movement setting and recommend further use of them to teach positive behaviors in 
physical education. Likewise the social story we used in our investigation reinforced the rules for behavior for the children who received Tier II intervention.

Implementing a Tier III intervention requires understanding the child and the reasons for his or her actions. Thus, students who continue to have difficulty following the rules despite the applications of Tier I and Tier II are evaluated with a functional behavior assessment to identify what drives the challenging behavior (Scott et al., 2010). Once the antecedent for the problem behavior is discovered, the teacher can determine the appropriate support for the student. In other words, that which precedes the misbehavior is "warded off", resulting in prevention of the problem behavior.

Having determined that Kaliyah attempted to gain attention in inappropriate ways, in the process alienating herself from her peers, we fostered cooperation between her and a peer by assigning another child to work with her that day. Having the consequence of being able to draw an item from the treasure box increased the likelihood of Kaliyah working together with another child. Such an arrangement also gave her the attention she was desiring, thus reinforcing acceptable behaviors.

Using an FBA with Madeline determined her need to gain control over her environment. Thus, her support was her placing the token (tiger paw) herself, giving her an appropriate way to establish control over her environment. Her behavior was contrary to the rule of respecting others, so when she demonstrated respect she was able not only to place her own token, she was also able to earn rewards when she accumulated enough tokens.

Our use of FBA in such a fashion corresponds to what Scott and colleagues (2010) consider the "greatest simplicity" (p. 524) for a Tier III intervention. They go on to state that much more intense FBA and subsequent intervention may be needed for children with more difficult behaviors. We found the interventions used with Kaliyah and Madeline to be effective for those two individuals.

Many teachers have difficulty facilitating cooperation and self-regulation in the physical education classroom. This study extends the knowledge base of positive behavior support (PBIS), giving physical educators a means to further develop skills for managing challenging behaviors. Researchers show PBIS has an established history of success in the classroom, but little research has been done on its use in physical education. That which has been done relies on specific strategies. Ours is the first research to organize several strategies into tiers to implement PBIS in physical education, thus providing educators a research-based method of increasing time available for learning.

\section{Limitations}

Because of the small size of the groups, this study is limited in its applicability to "real world" physical education classes. However, other aspects of the teaching labs such as (a) a specific set of rules for behavior, (b) teacher-made lesson plans 
with goals, (c) coed groups, and (d) a diverse range of skill levels within each group were factors that increased the similarities to school physical education.

This study was done in a summer school course, thus limiting the amount of time spent training the TCs to implement PBIS. Having more time for training could change the nature of the findings.

Another limitation is that one teacher candidate was responsible for making behavior marks while the other was teaching. We chose to have a partner TC record behavior in order to free the teaching TC from additional burden; however, typical implementation of PBIS has the teacher documenting behavior as well as teaching.

\section{Conclusions}

Our study supports previous research (Hinton et al., 2016; Rosser-Sandt \& Frey, 2005; Zimbelman et al., 2007) showing leveled supports such as behavior contracts, social stories, and visual prompts are successful in physical education. Post-test scores indicate all values of the categories of rules decreased from the pre-test; that is, students broke the rules less when instruction included PBIS. The Office of Special Education Programs (OSEP, 2015) explains that PBIS incorporates preemptive strategies that support students and teachers in addressing inappropriate behavior. Thus, when teachers act in ways that prevent challenging behavior they have more success in teaching and the students have more time in learning. Researchers (such as Muscott et al., 2008) found increased academic performance in subjects such as mathematics once PBIS was implemented on a schoolwide basis. Further, classroom ecology theory holds that reducing time in management can increase the time teachers and students have in instruction (Doyle, 1977; Hastie \& Siedentop, 2006). It follows, then, that the successful use of PBIS in physical education could lead to increased learning outcomes.

PBIS is an approach for being proactive (OSEP, 2015), and provides an important means of preventing misbehavior (Lavay et al. 2012). Our study illustrates a way to successfully organize these supports into tiers in physical education.

\section{Directions for Future Research}

We suggest that future research:

- continue to examine the implementation of PBIS in various physical education settings.

o investigate the impact of the use of PBIS on learning outcomes in physical education.

- Examine the impact of PBIS on the classroom ecology of the physical education class.

- investigate the teacher's implementation of PBIS while he or she is teaching a regular physical education class, rather than having an assistant record. 
- be conducted in regular physical education classes with larger groups of children, as part of the difficulty of large classes is the additional management strategies necessitated by number of children.

\section{References}

Alstot, A. (2012). The effects of peer-administered token reinforcement on jump rope behaviors of elementary physical education students. Journal of Teaching in Physical Education, 31, 261-278. https:// doi.org/10.1123/itpe.31.3.261

Cothran, D. J., Kulinna, P. H., \& Garrahy, D. A. (2009). Attributions for and consequences of student misbehavior. Physical Education and Sport Pedagogy, 14(2), 155-167. https:/ / doi.org/10.1080/17408980701712148

Doyle, W. (1977). Paradigms for research on teacher effectiveness. In L.S. Schulman (Ed.), Review of Research in Education (pp. 163-198). Itasca, IL: E.E. Peacock. https:// doi.org/10.2307/1167174

Dunlap, G., Hieneman, M., Knoster, T., Fox, L., Anderson, J., \& Albin, R.W. (2000). Essential elements of inservice training in positive behavior support. Journal of Positive Behavior Interventions, 2, 22-32. https://doi.org/10.1177/109830070000200104

Fernandez-Balboa, J. M. (1991). Beliefs, interactive thoughts, and actions of physical education student teachers regarding pupil misbehaviors. Journal of Teaching in Physical Education, 11, 59-78. https:// doi.org/10.1123/itpe.11.1.59

Graham, G., Holt-Hale, S.A., \& Parker, M. (2012). Children moving: A reflective approach to teaching physical education with movement analysis wheel. New York, NY: McGraw Hill.

Gray, C., \& Garand, J. (1993) Social stories: Improving responses of students with autism with accurate social information. Focus on Autistic Behavior, 8(1), 1-10. https://doi.org/10.1177/108835769300800101

Hastie, P.A., \& Siedentop, D. (2006). The classroom ecology paradigm. In D. Kirk, D. Macdonald, \& M. O'Sullivan (Eds.), The Handbook of Physical Education (pp. 214223). London, England: Sage. https:// doi.org/10.4135/9781848608009.n12

Hinton, V. M., \& Buchanan, A.M., \& Rudisill, M. E. (2016). A conceptual model of structured support in physical education. Preventing School Failure, 60(2). https://doi.org/10.1080/1045988x.2015.1111190

Johnson, E., Mellard, D., Fuchs, D., McKnight, M. for NRCLD (2006, August). Responsiveness to intervention (RtI): How to do it. Lawrence, KS: National Research Center on Learning Disabilities.

Kulinna, P. H., Cothran, D. J., \& Regualos, R. (2006). Teachers' reports of student misbehavior in physical education. Research Quarterly for Exercise and Sport, 77(1), 32-40. https:// doi.org/10.5641/027013606x13080769703768

Lavay, B. W., French, R., \& Henderson, H. L. (2006). Positive behavior management in physical activity settings. Champaign, IL: Human Kinetics.

Lavay, B., Henderson, H., French, R, \& Guthrie, S. (2012). Behavior management instructional practices and content of college/university physical education teacher education (PETE) programs. Physical Education and Sport Pedagogy, 17(2), 195-210, https://doi: 10.1080/17409989/2010.548063

LaVigna, G. W., \& Willis, T. J. (2012). The efficacy of positive behavior support with the most challenging behavior: The evidence and its implications. Journal of Intellectual and Developmental Disability, 37, 185-195. https://doi.org/10.3109/13668250.2012.696597

Muscott, H. S., Mann, E. L., \& LeBrun, M., R. (2008). Effects of large-scale implementation of schoolwide positive behavior support on student discipline and academic achievement. Journal of Positive Behavior Interventions, 10(3), 190205. https://doi.org/10.1177/1098300708316258 
Poling, A., Methot, L. L., \& LeSage, M. G. (1995). Fundamentals of behavior analytic research. New York: Plenum. https://doi.org/10.1007/978-1-4899-1436-1

Rosser-Sandt, D., \& Frey, G. (2005). Comparison of physical activity levels between children with and without autism spectrum disorders. Adapted Physical Activity Quarterly, 22, 146-159. https://doi.org/10.1097/00005768-200305001-00410

Sandt, D. (2008). Social stories for students with autism in physical education. Journal of Physical education, Recreation, and Dance, 79, 42-45. https://doi.org/10.1080/07303084.2008.10598198

Scott, T. M., Alter, P. J., Rosenberg, M., \& Borgmeier, C. (2010). Decision-making in secondary and tertiary interventions of school-wide systems of positive behavior support. Education and Treatment of Children, 33, 513-555. https:// doi.org/10.1353/etc.2010.0003

Simonsen, B., Fairbanks, S., Briesch, A., Myers, D., \& Sugai, G. (2008). Evidence-based practices in classroom management: Considerations for research to practice. Education and Treatment of Children, 31(3), 351-380. https://doi.org/10.1353/etc. 0.0007

Simonsen, B., \& Sugai, G. (2013). PBIS in alternative education settings: Positive support for youth with high-risk behavior. Education and Treatment of Children, 36, 3-14. https:// doi.org/10.1353/etc.2013.0030

U.S. Department of Education, Office of Special Education Programs Technical Assistance Center (2015). What is School-Wide PBIS? Retrieved from Office of Special Education Programs Technical Assistance Center website: http://www.pbis.org/school/default.aspx

Voorhees, M. D., Walker, V. L., Snell, M. E., \& Smith, C. G. (2013). A demonstration of individualized behavior support interventions by Head Start staff to address children's challenging behaviors. Research and Practice for Persons with Severe Disabilities, 38, 173-185. https://doi.org/10.2511/027494813809330324

Zimbelman, M., Paschal, A., Hawley, S. R., Molgaard, C. A., \& St. Romain, T. (2007). Addressing physical inactivity among developmentally disabled students through visual schedules and social stories. Research in Developmental Disabilities, 28(4), 386-396. https://doi.org/10.1016/j.ridd.2006.03.004 